Pacific Journal of Mathematics

ON A PROBLEM OF ILYEF 


\section{ON A PROBLEM OF ILYEFF}

\section{ZaLMAN RUBinstein}

Let $P(z)$ be a poIynomial whose zeros $z_{1}, z_{2}, \cdots, z_{n}(n \geqq 2)$ lie in $|z| \leqq 1$. It is shown that $P^{\prime}(z)$ always has a zero in $\left|z-z_{1}\right| \leqq 1$ if $\left|z_{1}\right|=1$ or if $\left|z_{1}\right|<1$ and $n=3,4$.

In his book Research Problems in Function Theory [2] W. K. Hayman mentions the following problem due to L. Ilyeff (Problem 4.5, p. 25): Let $P(z)$ be a polynomial whose zeros $z_{1}, z_{2}, \cdots, z_{n}(n \geqq 2)$ lie in $|z| \leqq 1$. Is it true that $P^{\prime}(z)$ always has a zero in $\left|z-z_{1}\right| \leqq 1$ ?

In this note we answer this question in the affirmative if $\left|z_{1}\right|=1$ for arbitrary $n$ and if $\left|z_{1}\right|<1$ for $n=3,4$. The case $n=2$ is trivial.

We also show that the disk $\left|z-z_{1}\right|<1$ always contains a zero of $P^{\prime}(z)$ regardless of the location of the zeros if $\left|P^{\prime}\left(z_{1}\right)\right|<n$ and if the polynomial $P(z)$ is normalized to be a monic polynomial.

\section{The boundary case.}

THEOREM 1. Let $P(z)$ be a polynomial whose zeros $z_{1}, z_{2}, \cdots, z_{n}$ $(n \geqq 2)$ lie in $|z| \leqq 1$ such that $\left|z_{1}\right|=1$. Then the disk $\left|z-z_{1}\right| \leqq 1$ always contains a zero of $P^{\prime}(z)$. Furthermore the disk $\left|z-z_{1}\right|<1$ always contains a zero of $P^{\prime}(z)$ except when $P(z)=c\left(z^{n}-e^{i \theta}\right)$.

Proof. Without loss of generality we may assume that $z_{1}=1$, $z_{k} \neq 1$ for $k=2,3, \cdots, n$ and $P^{\prime}(1)=1$. We shall show that the polynomial $P^{\prime}(z+1)$ has at least one zero in the closed unit disk. If this is not so then the following representation of $P^{\prime}(z+1)$ is possible [1] for $|z|<1$.

$$
P^{\prime}(z+1)=(1-z f(z))^{n-1}
$$

where $f(z)$ is analytic in the unit disk and less than one in modulus.

From (1) by differentiation we obtain

$$
P^{\prime \prime}(1)=(1-n) f(0) .
$$

The polynomial $Q(z)$ defined by the relation $P(z)=(z-1) Q(z)$ satisfies $Q(1)=P^{\prime}(1)=1$ and $2 Q^{\prime}(1)=P^{\prime \prime}(1)$. Hence applying (2) we obtain

$$
\begin{aligned}
Q^{\prime}(1)=\frac{Q^{\prime}(1)}{Q(1)}= & \frac{1}{1-z_{2}}+\frac{1}{1-z_{3}} \\
& +\cdots+\frac{1}{1-z_{n}}=\frac{1-n}{2} f(0)
\end{aligned}
$$


from which we deduce that $\left|Q^{\prime}(1)\right|<(n-1) / 2$. On the other hand since $\left|z_{k}\right| \leqq 1, \operatorname{Re} 1 /\left(1-z_{k}\right) \geqq 1 / 2$ and thus $\operatorname{Re} Q^{\prime}(1) \geqq(n-1) / 2$. This contradiction proves the theorem.

To prove the second part of the theorem we observe that $|f(z)| \leqq 1$ even if $P^{\prime}(z+1) \neq 0$ for $|z|<1$, so that in this case we also obtain a contradiction unless all the $z_{k}$ lie on the unit circumference and $f(z)$ is a constant of absolute value one. This implies that $P(z)$ has all its zeros on the unit circumference such that $P^{\prime}(z)$ has an $(n-1)$ fold zero on the circle $|z-1|=1$.

3. Third and fourth degree polynomials.

Theorem 2. Let $P(z)$ be a polynomial of degree three or four whose zeros lie in the closed unit disk. Then any circle of radius one about a zero of $P(z)$ contains a zero of $P^{\prime}(z)$.

Proof. We may assume that $P(z)=(z-x) Q(z)$, where $0<x<1$ and the zeros $z_{k}, k=1,2, \cdots, n$ of $Q(z)$ lie in $|z| \leqq 1$. We shall prove that the polynomial $f(z)=P^{\prime}(z+x)$ has a zero in $|z|<1$.

Consider the following polynomials

$$
\begin{aligned}
f(z) & =\sum_{k=0}^{n}(k+1) \frac{Q^{(k)}(x)}{k !} z^{k} \\
g(z) & =\sum_{k=0}^{n} \frac{1}{k-1}\left(\begin{array}{c}
n \\
k
\end{array}\right) z^{k}
\end{aligned}
$$

and

$$
h(z)=\sum_{k=0}^{n} \frac{Q^{(k)}(x)}{k !} z^{k} .
$$

By a result due to Szegö [4] every zero $\gamma$ of $h(z)$ has the form $\gamma=$ $-\alpha \beta$, where $\beta$ is a zero of $g(z)$ and $\alpha$ is a point belonging to a circular region containing all the zeros of $f(z)$. The zeros of $g(z)$ have the

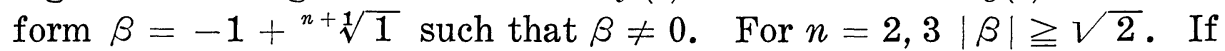
$f(z) \neq 0$ in $|z|<1$ we may choose $\alpha$ such that $|\alpha| \geqq 1$. Thus $|\gamma| \geqq \sqrt{2}$. Since $h(z)=Q(z+x)$ and $f(z)=P^{\prime}(z+x)$ it follows that all the zeros of $Q(z)$ satisfy $|z| \leqq 1$ and $|z-x| \geqq \sqrt{2}$ and no zero of $P^{\prime}(z)$ lies in $|z-x|<1$.

Consider now the polynomial $R(z)=P(z-1+x)=(z-1) Q_{1}(z)$, where $Q_{1}(z)=Q(z-1+x)$. No zero of $R^{\prime}(z)$ lies in $|z-1|<1$. By Theorem 1 we shall obtain a contradiction if we can show that all the zeros of $Q_{1}(z)$ lie in $|z|<1$. Indeed the zeros of $Q_{1}(z)$ satisfy the inequalities $|z-1+x| \leqq 1$ and $|z-1| \geqq \sqrt{2}$. A straightforward calculation shows that if $z=u+i v$ these inequalities imply 


$$
u^{2}+v^{2} \leqq 3-\left(x+\frac{1}{x}\right)<1
$$

for $0<x<1$. This completes the proof.

\section{A particular class of polynomials.}

THEOREM 3. Let $P(z)=z^{n}+a_{n-1} z^{n-1}+\cdots+a_{0}$. If $P\left(z_{1}\right)=0$ and $\left|P^{\prime}\left(z_{1}\right)\right|<n$, then $P^{\prime}(z)$ has a zero in $\left|z-z_{1}\right|<1$.

Proof. Write $P(z)=\left(z-z_{1}\right) Q(z)$ and set $f(z)=P^{\prime}\left(z+z_{1}\right)$ and $f^{*}(z)=z^{n-1} \bar{f}(1 / z)$. We have $f\left(e^{i \theta}\right)=f^{*}\left(e^{i \theta}\right)$ and

$$
\begin{aligned}
f(z) & =n z^{n-1}+\cdots+Q\left(z_{1}\right) \\
f^{*}(z) & =\overline{Q\left(z_{1}\right)} z^{n-1}+\cdots+n .
\end{aligned}
$$

If $Q\left(z_{1}\right) \neq 0$ the polynomial $n f^{*}(z)-\overline{Q\left(z_{1}\right)} f(z)$ is of degree not exceeding $(n-2)$ and since $Q\left(z_{1}\right)=P^{\prime}\left(z_{1}\right)$ it follows by Rouché's theorem that $f^{*}(z)$ has at most $(n-2)$ zeros in $|z|<1$. Therefore $f(z)$ has at least one zero in $|z|<1$. This means that $P^{\prime}(z)$ has at least one zero in $|z-x|<1$. If $Q\left(z_{1}\right)=0$ then $P^{\prime}\left(z_{1}\right)=0$ and the same is true. From Theorem 3 we can deduce that Ilyeff's conjecture is true if all the coefficients of $Q(z)$ are less than one in modulus. This includes in particular the case where the theorem of Enström-Kakeya [3] is applicable, i.e. when the coefficients of $Q(z)$ form a monotonically decreasing sequence of positive numbers.

\section{BIBLIOGRAPHY}

1. J. Dieudonné, Sur quelques applications de la théorie des fonctions bornées aux polynômes dont toutes les racines sont dans un domain circulaire donné, Actualités Scient. et Industri. 114 (1934), 5-24.

2. W. K. Hayman, Research Problems in Function Theory, The Athlone Press, London, 1967.

3. M. Marden, The Geometry of Polynomials, Mathematical Surveys No. III, 2nd ed., Amer. Math. Soc., Providence, 1966.

4. G. Szegö, Bemerkungen zu einem Satz von J. H. Grace über die Wurzeln algebraischer Gleichungen, Math. Zeit. 13 (1922), 28-55.

Received April 24, 1967. This work was supported in part by the National Science Foundation GP-5221.

Clark University 



\section{PACIFIC JOURNAL OF MATHEMATICS}

\section{EDITORS}

\author{
H. ROYDEN \\ Stanford University \\ Stanford, California \\ R. R. Phelps \\ University of Washington \\ Seattle, Washington 98105
}

J. DUGUNDJI

Department of Mathematics

University of Southern California

Los Angeles, California 90007

RICHARD ARENS

University of California

Los Angeles, California 90024

\section{ASSOCIATE EDITORS}
E. F. BECKENBACH
B. H. NeumanN
F. WOLF
K. YosidA

\section{SUPPORTING INSTITUTIONS}

UNIVERSITY OF BRITISH COLUMBIA

CALIFORNIA INSTITUTE OF TECHNOLOGY

UNIVERSITY OF CALIFORNIA

MONTANA STATE UNIVERSITY

UNIVERSITY OF NEVADA

NEW MEXICO STATE UNIVERSITY

OREGON STATE UNIVERSITY

UNIVERSITY OF OREGON

OSAKA UNIVERSITY

UNIVERSITY OF SOUTHERN CALIFORNIA
STANFORD UNIVERSITY

UNIVERSITY OF TOKYO

UNIVERSITY OF UTAH

WASHINGTON STATE UNIVERSITY

UNIVERSITY OF WASHINGTON

AMERICAN MATHEMATICAL SOCIETY CHEVRON RESEARCH CORPORATION TRW SYSTEMS

NAVAL WEAPONS CENTER

Printed in Japan by International Academic Printing Co., Ltd., Tokyo, Japan 


\section{Pacific Journal of Mathematics}

\section{Vol. 26, No. $1 \quad$ November, 1968}

Efraim Pacillas Armendariz, Closure properties in radical theory......... 1

Friedrich-Wilhelm Bauer, Postnikov-decompositions of functors .......... 9

Thomas $\mathrm{Ru}-$ Wen Chow, The equivalence of group invariant positive definite

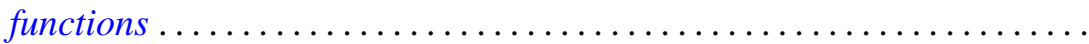

Thomas Allan Cootz, A maximum principle and geometric properties of

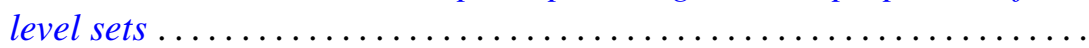

Rodolfo DeSapio, Almost diffeomorphisms of manifolds ............ 47

R. L. Duncan, Some continuity properties of the Schnirelmann density......

Ralph Jasper Faudree, Jr., Automorphism groups of finite subgroups of

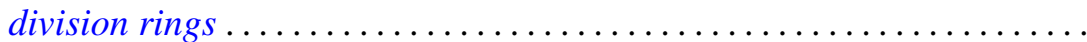

Thomas Alastair Gillespie, An invariant subspace theorem of $J$.

Feldman.........................................

George Isaac Glauberman and John Griggs Thompson, Weakly closed direct factors of Sylow subgroups .............................

Hiroshi Haruki, On inequalities generalizing a Pythagorean functional equation and Jensen's functional equation .....................

David Wilson Henderson, D-dimension. I. A new transfinite dimension.....

David Wilson Henderson, D-dimension. II. Separable spaces and

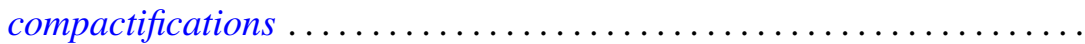

Julien O. Hennefeld, A note on the Arens products ............... 115

Richard Vincent Kadison, Strong continuity of operator functions ...

J. G. Kalbfleisch and Ralph Gordon Stanton, Maximal and minimal coverings of $(k-1)$-tuples by $k$-tuples.

Franklin Lowenthal, On generating subgroups of the Moebius group by pairs of infinitesimal transformations...

Michael Barry Marcus, Gaussian processes with stationary increments possessing discontinuous sample paths . .

Zalman Rubinstein, On a problem of Ilyeff ...

Bernard Russo, Unimodular contractions in Hilbert space. ...

David Lee Skoug, Generalized Ilstow and Feynman integrals...

William Charles Waterhouse, Dual groups of vector spaces . 